\title{
Concepções pedagógicas da área de Filosofia do Colégio de Aplicação da UFRGS: teorias e práticas a partir do filosofar com conceitos
}

\begin{abstract}
Resumo:
Neste trabalho, gostaríamos de justificar a escolha pelo pensar a partir de conceitos como proposta pedagógica para o ensino de Filosofia e mostrar alguns ganhos para o ensino-aprendizagem de Filosofia por conta desta opção. Defenderemos que o pensar com conceitos permite, a um mesmo tempo, a atividade específica da Filosofia e também o diálogo com outras áreas do conhecimento. Espera-se com esse trabalho apresentar algumas diretrizes curriculares para o ensino de Filosofia que revelem a importância dessa área para a qualificada capacitação dos estudantes da educação básica para o exercício do pensar autônomo. Compartilhamos um exemplo prático de sala de aula para ilustrar o trabalho que iniciamos na área de Filosofia do Colégio de Aplicação da UFRGS.
\end{abstract}

\section{Palavras-chave:}

Ensino de Filosofia. Pensar com conceitos. Currículo.

\begin{abstract}
:
In this paper, we would like to justify the choice for the thinking with concepts as a pedagogical proposal in Philosophy teaching, and to share some of its gains for teaching and learning Philosophy. We will advocate that thinking with concepts enables, at the same time, the specific task of Philosophy and the dialogue with other knowledge areas. In this paper, we hope to present some curricular guidelines for the Philosophy teaching that reveal the importance of this area for the qualified training of scholar students on the exercise of autonomous thinking. We share a classroom practical example to illustrate the work that we are beginning in the Philosophy field at Colégio de Aplicação da UFRGS.
\end{abstract}

\section{Keywords:}

Philosophy teaching. Thinking with concepts. Curriculum.

\footnotetext{
* Doutora em Filosofia. Professora do Colégio de Aplicação da UFRGS. E-mail: rubiavogt@yahoo.com. ORCID iD: https://orcid.org/0000-0001-7105-7352.

** Doutor em Filosofia. Professor do Colégio de Aplicação da UFRGS. E-mail: raf.cortes@yahoo.com.br. ORCID iD: https://orcid.org/0000-0002-6970-6701.
} 


\section{Introdução}

O percurso do ensino de Filosofia na educação contemporânea no Brasil é acidentado. Em boa parte, essa trajetória é irregular por conta das alternâncias entre a obrigatoriedade e a não obrigatoriedade da Filosofia nos currículos da educação básica, pois sempre que a Filosofia é pouco incentivada a figurar nas escolas, a reflexão e produção da área de ensino de Filosofia entram em ocaso.

Apesar dos percalços, duas concepções para o ensino de Filosofia se firmaram: a primeira, e mais tradicional, o ensino a partir da História da Filosofia, e a segunda, mais recente, o ensino a partir de problemas filosóficos. No entanto, nem sempre essas duas possibilidades foram se constituindo em diálogo, nem atuaram conjuntamente na sala de aula. Mais recentemente, tem-se discutido o papel dos conceitos no ensino de Filosofia, e esta pode ser uma estratégia para conciliar a História da Filosofia e os problemas filosóficos na escola. De fato, apesar das limitações do modelo de ensino circunscrito à História da Filosofia - ainda mais se essa for apresentada como linear e cumulativa —, o ensino via problemas não exclui a História da Filosofia, pois como nos recorda Marcondes (2004, p. 59), "a história da filosofia pode contribuir para despertar o interesse por questões filosóficas através do contato com as obras dos grandes pensadores que primeiro as formularam".

Neste artigo, pretendemos justificar a escolha da área de Filosofia do CAp-UFRGS por um ensino a partir de conceitos, apresentando alguns possíveis benefícios desta escolha; além disso, propomo-nos a compartilhar um recorte de experiência de sala de aula onde aplicamos as orientações pedagógicas da área.

\section{Metodologia}

Este trabalho emerge, essencialmente, da prática pedagógica da sala de aula. Assim, ele surge a partir das inquietações docentes provocadas pelos erros e acertos da e do docente nos seus processos de ensino. Trata-se, portanto, de um trabalho freiriano, pois está circunscrito ao que consta no tópico 1.8 de Pedagogia da Autonomia, denominado "Ensinar exige reflexão crítica sobre a prática": "O pensar certo sabe, por exemplo, que não é a partir dele como um dado dado, que se conforma a prática docente crítica, mas sabe também que sem ele não se funda aquela. A prática docente crítica, implicante do pensar certo, envolve o movimento dinâmico, dialético entre o fazer e o pensar sobre o fazer" (FREIRE, 2002, p. 18).

As experiências exitosas estimulam a buscar fundamentar sempre mais qualificadamente nossos pressupostos pedagógicos. Já as dificuldades postulam a necessidade de maior estudo e qualificação. Ou seja: a e o docente de Filosofia do CAp-UFRGS dedicam-se constantemente a leituras, produção de trabalhos acadêmicos, socialização e discussão de seus estudos e textos com os pares da área de ensino de Filosofia e da área da Educação em geral. Entendemos ser importante explicar que a docência de Filosofia na educação básica requer tanto o constante aprimoramento voltado para a sala de aula, quanto o inesgotável estudo da Filosofia. Outra consideração que não queremos deixar de compartilhar é que a e o docente de Filosofia do CAp-UFRGS conduzem a atuação da área de forma integrada e dialogada. Assim, sem menosprezar as características pedagógicas de cada um desses docentes, independente de quem esteja ministrando determinado plano ou aula, o pano de fundo é uma construção coletiva, fundamentada no projeto pedagógico da área.

\section{O ensino por conceitos: uma alternativa conciliadora entre a história da Filosofia e os problemas filosóficos}

A presença da Filosofia na educação básica brasileira é intermitente. Inicialmente, sua participação se dava como uma disciplina clássica, principalmente nos colégios confessionais. A Filosofia aterrissa na educação brasileira pelas mãos dos jesuítas, tanto nas escolas quanto nos cursos de formação superior, 
fossem eles programas voltados para a elite cultural, fossem a preparação para o ministério sacerdotal. O ensino escolástico, centrado na leitura e interpretação de Aristóteles e de Tomás de Aquino ${ }^{1}-$ e com a proibição de certas leituras ${ }^{2}$ - centrava-se em exercícios cujos objetivos eram a erudição e a retórica.

$\mathrm{Na}$ segunda metade do século XVIII, com as reformas pombalinas, outras ordens, como os franciscanos, e também leigos passam a ministrar as aulas régias. Contudo, “[...] do ponto de vista pedagógico, houve pouca mudança, visto que os professores continuavam sendo filhos de proprietários rurais formados em colégios jesuítas. O ensino em geral continuava com os mesmos objetivos religiosos e livrescos, o mesmo ocorrendo com o ensino de filosofia de tendência escolástica" (HORN, 2000, p. 21).

A Filosofia segue presente na educação brasileira no século XIX, e assim avança para o século XX. Ainda sobre o século XIX, de acordo com Horn (2000, p. 22), "nas províncias, a filosofia já era incluída obrigatoriamente no currículo dos liceus e dos ginásios do curso secundário desde o início do século [...]". A Filosofia resiste nos currículos com o advento da República (1889) e não esmorece diante das reformas na educação brasileira na primeira metade do século XX, mesmo que com presença parcial, especialmente nos anos finais do que hoje entendemos por educação básica. Contudo, em 1961, a Lei no 4.024 relegou a Filosofia ao status de disciplina complementar - e não mais obrigatória - e isso tão somente se assim indicassem os conselhos estaduais de educação. Em seguida, "com o golpe político de 64, tornou-se uma mera disciplina optativa, com sua presença na grade curricular passando a depender da direção do estabelecimento de ensino [...]" (HORN, 2000, p. 28).

As reflexões sobre ensino de Filosofia ficaram praticamente em estado de inanição a partir do período da Ditadura Militar (1964-1985) no Brasil. Embora não tenha sido proibida pelo regime de exceção, a presença da Filosofia na educação básica foi fortemente desincentivada nesse período. ${ }^{3}$ Além de não ser mais disciplina obrigatória por força de lei, não houve significativas políticas públicas, como formação de professores e publicação de material didático.

Neste contexto de pouca discussão sobre ensino de Filosofia, a História da Filosofia - ou melhor dizendo, uma determinada compreensão de História da Filosofia — se apresentou como uma metodologia ${ }^{4}$ possível para a disciplina. Nesta perspectiva, a Filosofia e sua história se amalgamam, e "[...] ensinar filosofia significa ensinar o que a história da filosofia produziu até hoje - mesmo que dificilmente se chegue até os filósofos do presente. Geralmente essa história é compreendida como os mais de 25 séculos de existência da filosofia ocidental e seus desdobramentos" (GALLO; KOHAN, 2000, p. 177).

Pode-se estudar os filósofos em sequência, ou um conteúdo ao longo do tempo, ou mesmo um conteúdo em determinado filósofo.

A História da Filosofia vem recebendo críticas tanto enquanto uma área da Filosofia, quanto como um método de ensino. Não nos concerne, no escopo deste trabalho, desenvolver as críticas voltadas para a

\footnotetext{
1. Rouanet (1987, p. 320) avalia que "o que havia de errado nos antigos manuais jesuítas não era o fato de serem tomistas, e sim o de serem esquemáticos e simplistas".

2. “O receio de 'influência perniciosa' que o pensamento moderno poderia exercer, encaminhando a deísmo, ateísmo e materialismo, levou a Real Mesa Censória a proibir a leitura de Locke, Hobbess, Rousseau, Espinosa e Voltaire, dentre outros” (HORN, 2001, p. 19). 3. Nesse sentido, Rouanet (1987, p. 307) assim rememora: “Começamos então a descobrir uma coisa estranha: uma causalidade oblíqua, perversa, inesperada, entre o fim das humanidades e o fortalecimento do regime autoritário. Que o regime tinha acabado com as humanidades era algo de óbvio, que podia ser verificado no Diário Oficial; mas que a proposição era reversível e que a extinção das humanidades beneficiava o regime foi algo que só descobrimos depois de algum tempo". Por fim, o autor arremata: "é óbvio que uma disciplina que tem a crítica como razão de ser não pode ser estimulada pelos regimes autoritários" (ROUANET, 1987, p. 320). Por outro lado, Gallo e Kohan (2000, p. 174-175) ponderam que: "Porém, o golpe dado pela ditadura, com a exclusão da Filosofia, também produziu um efeito contrário. A exclusão da Filosofia pelos militares possibilitou que ela fosse percebida inequivocamente pela sociedade como uma ferramenta educacional ligada à democracia e, portanto, a uma cidadania não autoritária. [...] Os militares, com sua exclusão da Filosofia, contribuíram para fixá-la como prática revolucionária no imaginário social”. 4. Gallo e Kohan (2000, p. 177) falam em "paradigmas para o ensino de Filosofia, muitas formas que moldam a prática dos professores de Filosofia no Ensino Médio no Brasil". Compartilhamos do alerta que indica alguns limites e possibilidades ao tentarmos delinear estas metodologias: "Tratam-se de modelos quase caricaturados que, como tais, podem ter pouca corroboração empírica. Porém, nosso interesse não é descrever uma realidade, mas oferecer elementos analíticos que permitam compreendê-la. Portanto, não se deve ler esta categorização com qualquer pretensão positiva de 'dar conta de', mas com o intuito de estabelecer categorias que permitam situar-nos numa prática complexa e multidimensional” (GALLO; KOHAN, 2000, p. 177).
} 
configuração como uma área da Filosofia. Tampouco vamos desenvolver prolongadamente os óbices postos em relação ao ensino via História de Filosofia. De qualquer modo, destacamos algumas reflexões.

Primeiramente, falar em História da Filosofia é pressupor uma data e um local de nascimento para este campo do saber, qual seja, o século VI a.C. na Grécia Antiga. Embora não se possa, de modo algum, minimizar a influência dos antigos gregos, também não se pode ignorar os saberes - e os conhecimentos e sabedoria - de outros povos da Antiguidade. Como afirma Noguera (2014, p. 12), “[...] a filosofia não tem um local de nascimento". Mais grave é este nascedouro definir a Filosofia como um produto ocidental (e, por muito tempo, europeu), negando a influência oriental (e negra) dos próprios primeiros filósofos. ${ }^{5}$

A História da Filosofia dá a entender, muitas vezes, que é possível apreender todo o passado. Além de ser esta uma tarefa inexequível, infelizmente é notável também o apagamento de alguns temas e autores, como por exemplo, as mulheres - as filósofas - ao longo da História da Filosofia.

A História da Filosofia, em seus esquemas temporais, por um lado reúne autores de um mesmo tempo que, por vezes, pouco tiveram de comum entre si, e por outro, separa temporalmente questões que se mantiveram vivas em diferentes momentos históricos. Nesse sentido, Marcondes (2004, p. 60) alerta que

[...] a história da filosofia deve ser vista assim como história não da tradição em seu sentido doutrinário, ou como história dos grandes sistemas, mas sim como contendo a contribuição dos grandes filósofos ao introduzirem questões que até hoje nos motivam a pensar, e como indicando os vários modos como essas questões foram tratadas. Deve ser vista também não como linear ou contínua, mas como incluindo o intenso debate entre os vários filósofos e as várias correntes de pensamento, as críticas, rupturas, controvérsias, polêmicas que já se encontram no início mesmo da filosofia com a crítica de Parmênides aos mobilistas, de Platão aos sofistas e de Aristóteles aos platônicos. A tradição filosófica é uma grande história das polêmicas, mais do que da formação progressiva de um saber ou da constituição de uma doutrina.

Retomando o percurso do ensino de Filosofia na educação básica brasileira, destacamos que, mesmo com o fim do nefasto período da Ditadura Civil-Militar no Brasil, a Filosofia não voltou imediatamente aos currículos como disciplina obrigatória. Muito pelo contrário, levou mais de vinte anos para que esta disciplina voltasse a figurar, por força de lei, na educação básica brasileira. Embora a obrigatoriedade da Filosofia tenha sido restrita ao Ensino Médio, as mudanças provocadas a partir do Parecer CNE/38 DE 2006 são perceptíveis. Por força do referido Parecer, a Lei de diretrizes e bases da educação nacional (Lei no 9.394/96, conhecida como LDB) foi alterada, de modo a acolher em seu texto a obrigatoriedade da Filosofia no Ensino Médio.

Com essas mudanças, as reflexões sobre o ensino de Filosofia tomaram novo ânimo e a Filosofia, enquanto disciplina da educação básica, foi contemplada, por exemplo, nas Orientações Educacionais Complementares aos Parâmetros Curriculares Nacionais $(2002)^{6}$ e nas Orientações Curriculares para o Ensino Médio (2006) ${ }^{7}$. Outra medida de destaque é a entrada da Filosofia no Plano Nacional do Livro Didático em 2012.

No bojo dessas discussões, com renovado fôlego, ${ }^{8}$ a comunidade de ensino de Filosofia no Brasil passou a defender, nas suas posições de vanguarda, uma nova perspectiva: o ensino a partir dos problemas

\footnotetext{
5. Para saber mais sobre esta temática, recomendamos a leitura de Noguera (2014), que nos informa, por exemplo, que Tales de Mileto, Anaximandro, Anaxímenes e Pitágoras estudaram no Egito, tendo o último vivido mais de duas décadas por lá.

6. BRASIL. Orientações Curriculares para o Ensino Médio - Ciências Humanas e suas Tecnologias. Brasília, DF: MEC/Secretaria de Educação Básica, 2006.

7. BRASIL. Orientações Educacionais Complementares aos Parâmetros Curriculares Nacionais. Brasília, DF: MEC/Secretaria de Educação Básica, 2002. 8. Para maiores dados sobre o impacto dessas mudanças na área de Filosofia, e mais especificamente, na área de ensino de Filosofia, recomendamos a leitura do artigo "Ensino de Filosofia como campo de conhecimento", de Patrícia Del Nero Velasco. Neste trabalho, a autora analisa: coleções, revistas, eventos, PROF-FILO e iniciativas da Associação Nacional de Pós-Graduação em Filosofia (ANPOF), desde o final da década de 1990; e os números de projetos de pesquisa, extensão e ensino, artigos, livros, capítulos e trabalhos completos dos membros do Grupo de Trabalho Filosofar e Ensinar a Filosofar, da ANPOF, ano a ano, em dois blocos de década (1997-2007 e 2008-2018). No artigo, fica demonstrado o salto (ao menos numérico) das mais variadas ações e produções na área de ensino de Filosofia a partir da obrigatoriedade da Filosofia no Ensino Médio.
} 
da Filosofia, isto é, das questões, perguntas, temas que inquietam (ou inquietaram) a Filosofia'. Gallo e Kohan (2000, p. 179) asseveram que "neste caso, temos um ensino menos enciclopédico e mais ativo, uma vez que o referencial de trabalho deixa de ser o conteúdo histórico para abarcar problemas a serem repensados, retrabalhados pelos alunos".

Encontramos uma síntese da posição daqueles que defendem que se aborde a Filosofia através de seus problemas em Porta (2014, p. 17):

[...] proponho-me a oferecer uma opção à didática e metodologia do estudo filosófico com base no seguinte princípio: a compreensão do problema deve constituir o núcleo essencial, o eixo, tanto de ensino quanto da aprendizagem da filosofia. Não é possível "entender" filosofia se não se entende "o problema" abordado por um filósofo. Entretanto, "o problema" tende a ser pressuposto ou simplesmente ignorado, sem que se dedique esforço específico algum para esclarecê-lo.

O viés dos problemas filosóficos ganhou a centralidade nas discussões sobre ensino de Filosofia a partir do final da década de 90. Entendemos que essa abordagem apresenta algumas possibilidades que consideramos mais profícuas do que o trabalho com a História da Filosofia, dentre as quais podemos citar, para exemplificação: se a Filosofia em si é um problema, se defini-la é um problema - como o é - faz sentido escrutiná-la a partir de seus problemas. Ainda, em sala de aula, os problemas filosóficos permitem que as e os estudantes se engajem na avaliação da questão proposta, envolvendo-as(os) inclusive com seu posicionamento pessoal, desde que este seja fundado em argumentos, evidências (visto que a Filosofia não é amiga das opiniões infundadas, ao estilo das que abundam em nossos dias). Outro modo de buscar uma participação ativa dos(as) estudantes em sala de aula é convidá-los(as) a selecionar os problemas a serem trabalhados.

$\mathrm{Na}$ avaliação da área de Filosofia do CAp-UFRGS, embora a História da Filosofia não deva assumir a centralidade das aulas, sua presença também não é desprezível. Um dos ganhos que vislumbramos é a contextualização que a História permite. Se pensarmos nos grandes períodos (Filosofia Antiga, Filosofia Medieval, Filosofia Moderna e Filosofia Contemporânea), podemos apreender alguns fatores, como, por exemplo, as condições sociais e econômicas que circundavam as questões de cada época. Se focarmos no contexto em que cada pensador(a) esteve inserido(a), podemos buscar a que se ligavam os problemas por ele(a) levantados. Isso não é fundamental, mas é complementar aos problemas filosóficos, situando-os também sócio-historicamente para as(os) alunas(os). Algumas vezes, também, nos deparamos com um problema que foi abordado por diferentes autores(as) em um mesmo período temporal, como, por exemplo, o contratualismo na Idade Moderna. Nestes casos, é interessante notar como a discussão de cada pensador se apoiou em escritos anteriores, no que avançou, e no que se propôs a ser diferente.

Na prática escolar cotidiana, postular um problema filosófico nem sempre é tarefa fácil. Algumas dificuldades são de ordem prática, como por exemplo: em uma hora-aula, a qual não configura nem sessenta minutos, muitas vezes não há tempo hábil para contextualizar apropriadamente um problema, ou para apresentar, desenvolver e analisá-lo. Ainda, entre uma aula de Filosofia e a próxima, parte do aprendizado pode não ter sido bem apreendida e se dissipa, de modo que é preciso retomar aquilo que já se abordou, retardando o avanço na questão em pauta. Outras vezes, a lista de conteúdos a ser vencida não permite uma atenção dedicada a cada problema filosófico. Ou, ainda, o tempo escolar, com trimestres (ou outra fração de tempo) que nos exigem o encerramento de unidades temáticas, inviabiliza um trabalho mais qualificado com os problemas filosóficos.

Outra dificuldade pode advir da complexidade inerente às questões filosóficas sobre o conhecimento, a ética, a linguagem, a arte, a existência. Essas questões não foram pensadas para estudo e discussão no ambiente escolar. Muitas vezes, portanto, é necessário mediar a colocação do problema, e um grande aliado dessa estratégia é o conceito. Assim, o trabalho com conceitos não é exatamente uma terceira via entre

9. Gallo e Kohan (2000, p. 178-179), observam que “[...] a própria pergunta ‘o que é um problema filosófico?’ é uma questão filosófica e, portanto, contestável, controversa, e isto é aproveitado por muitos professores que começam seus cursos problematizantes precisamente colocando a própria delimitação e natureza da Filosofia como problema". 
História da Filosofia e problemas da Filosofia, nem se configura em uma proposta distinta da abordagem via problemas filosóficos. Os conceitos são um recorte, um ajuste focal, uma centralidade para o trabalho com os problemas.

Sobre a relação entre a Filosofia - e o filosofar - e os conceitos, Deleuze e Guattari (2010, p. 11), expõem: “O filósofo é o amigo do conceito, ele é conceito em potência. Quer dizer que a filosofia não é uma simples arte de formar, de inventar ou de fabricar conceitos, pois os conceitos não são necessariamente formas, achados ou produtos. A filosofia, mais rigorosamente, é a disciplina que consiste em criar conceitos".

Gallo e Kohan (2000) corroboram a tese da Filosofia como criadora de conceitos. Para esses autores, a pensamento é um pensamento conceitual. E diz-se que a Filosofia cria conceitos no sentido de "[...] uma apreensão, a configuração de um acontecimento, que não se confunde com o estado de coisas. O conceito destaca o acontecimento das coisas para circunscrevê-lo [...]" (GALLO; KOHAN, 2000, p. 192).

É preciso, então, trazer o(s) conceito(s) para as aulas de Filosofia. Wilson (2005), ciente de que nem toda palavra é um conceito, propõe uma metodologia para sabermos se estamos diante de um conceito. A distinção inicial do autor é entre fatos, valores e conceitos. Um ponto de destaque na proposta de Wilson é sua busca pelo conceito por meio de perguntas. Ao levantar perguntas, o estudo dos conceitos viabiliza outra grande característica do filosofar, a saber, o perguntar, que é um meio privilegiado de ensinar a filosofar desde a tradição dos diálogos socráticos.

De acordo com Wilson (2005, p. 3), para respondermos uma pergunta sobre fatos “[...] precisamos apenas de conhecimento sobre o mundo e sobre algumas das coisas que existem no mundo"; as perguntas sobre valores são aquelas de juízo de valor. ${ }^{10}$ Já as perguntas sobre conceitos constituem um dos fazeres da Filosofia e "[...] têm a ver com os usos das palavras e com os critérios ou princípios pelos quais os usos são determinados" (WILSON, 2005, p. 11).

Conforme já postulamos, os conceitos são aliados dos problemas filosóficos. Se, por um lado, os conceitos podem introduzir os problemas, por outro eles também podem ser postos como a definição do que está em questão. Por exemplo, em se tratando de ética, do que é certo ou errado, estamos lindando com o conceito de "justiça” (além dos próprios conceitos de "ética”, "certo" e "errado"). A análise conceitual pode promover o isolamento do problema em questão para um exame minucioso, e pode também melhor localizá-lo na história das ideias. E a relação da Filosofia com os conceitos é intrínseca, pois podemos localizar conceitos nas mais variadas produções filosóficas. Aos situá-los na História da Filosofia, podemos promover, ainda, uma conciliação entre as perspectivas historicistas e problematas.

Os conceitos são ainda um caminho viável para o diálogo interdisciplinar, relação esta prezada pela área de Filosofia do CAp-UFRGS. Ao pensarmos a Filosofia na educação básica, em especial no Ensino Médio, destaca-se a função "pedestre”, conforme a concebe Rocha (2015, p. 49): "conceitos e temas filosóficos nas disciplinas escolares que podem ser trabalhados pelo professor de Filosofia [...]”. A Filosofia, como um pedestre que circula, pode operar com esses conceitos transversais que atravessam outros componentes curriculares e a labuta conceitual de ordem filosófica.

Com tantas disciplinas, se não houver interação, ficamos diante do modelo mineral, em que cada área do saber figura como um componente isolado, sem diálogo, como que crescendo em justaposição. ${ }^{11}$ A transversalidade pedestre pode promover o

10. Um dos exemplos de perguntas por valor de Wilson $(2005$, p. 7) é: “O comunismo é um sistema desejável de governo?” Em seguida (p. 8), ele explica por que seria essa uma pergunta por valores: “A [...] pergunta [...] pede que atribuamos algum valor ao comunismo: pergunta-nos se ele é bom ou mau, sábio ou não, se está certo ou errado, se, em termos políticos, é desejável ou indesejável. A segunda pergunta, portanto, é questão de juízo de valor".

11. Outra metáfora para esse tipo de currículo é o presépio: "Podemos pensar o currículo como um presépio no qual cada professor deposita sua oferta de formação e faz assim crescer a árvore-currículo mediante a agregação de boas vontades? Quando o projeto político-pedagógico de uma escola é concebido com base no princípio do presépio ele se transforma em um documento para alimentar a burocracia, pois não se leva em conta o que acontece na disciplina ao lado; cada um faz por si, o professor é maior abandonado e o planejamento curricular vira uma peça de ficção" (ROCHA, 2015, p. 27). 
[...] exame de conceitos que tem livre curso nas demais disciplinas, mas não são tratados em nenhuma delas: verdade, causa, abstração, infinito, ser etc. As perguntas que dizem respeito a esses conceitos, em certo sentido, excedem das outras disciplinas, elas podem se originar nas atividades das demais disciplinas escolares e nelas não encontram respostas; elas podem ir se acumulando na prateleira das curiosidades colecionadas pelo aluno e ficam ali, sem respostas satisfatórias. (ROCHA, 2015, p. 44).

Uma das vias de diálogo da Filosofia com os demais componentes curriculares pode se concretizar, portanto, no escrutínio filosófico de conceitos empregados em outras áreas do conhecimento.

\section{Resultados e discussão}

Entendemos que o resultado de nossas discussões é nossa prática de sala de aula. Assim, apresentaremos, na sequência, um recorte de um plano de ensino fundamentado no trabalho com conceitos. Para melhor compreensão da atuação da área, procederemos a uma explicação do atual quadro e inserção da Filosofia no CAp-UFRGS, conforme segue. A área de Filosofia conta com dois professores efetivos desde 2011. A Filosofia é componente curricular obrigatório no Ensino Médio "Regular" e nos Ensinos Fundamental e Médio da modalidade de Educação de Jovens e Adultos (EJA). A área atua, também, em outras atividades de ensino da escola, em especial, nas equipes de trabalho do Ensino Médio e da EJA, tais como disciplinas eletivas, disciplinas flutuantes, projetos de investigação e oficinas. No Ensino Médio, a disciplina conta com dois períodos semanais em cada turma de cada ano. Na EJA, conforme a configuração do projeto pedagógico da equipe, a Filosofia atua no Bloco de Conhecimento das Ciências Humanas, junto à Geografia, à História e à Sociologia. O Bloco tem o espaço curricular de uma noite semanal de cinco períodos em cada uma das etapas de Ensinos Fundamental e Médio.

O recorte escolhido faz parte de um plano de ensino da EJA, o qual propõe um problema que transite entre a ética e a política. No semestre em questão, tratamos o problema da violência, e nos perguntamos quando o Estado poderia agir legitimamente com violência. Fugimos aos exemplos mais corriqueiros, como o de uso de força militar e policial, e focamos a questão da educação como um direito. A violação do direito à educação faz todo sentido às(aos) educandas(os) da EJA, que tiveram suas trajetórias escolares interrompidas e voltam à escola em resgate aos seus direitos.

Em determinado momento do plano de ensino, as(os) estudantes procederam à leitura de trechos selecionados da Pedagogia do Oprimido, de Paulo Freire, não sem antes conversarmos sobre as ações e o legado do patrono da educação brasileira. Focamos os seguintes conceitos: opressores-oprimidos, com a caracterização dos opressores e dos oprimidos, e práxis e educação libertadora. Para Freire (1987, p. 16-17), a relação entre opressores e oprimidos é marcada pela violência:

Daí que, estabelecida a relação opressora, esteja inaugurada a violência, que jamais foi até hoje, na história, deflagrada pelos oprimidos. Como poderiam os oprimidos dar início à violência, se eles são o resultado de uma violência? Como poderiam ser os promotores de algo que, ao instaurar-se objetivamente, os constitui? Não haveria oprimidos, se não houvesse uma relação de violência que os conforma como violentados, numa situação objetiva de opressão. Inauguram a violência os que oprimem, os que exploram, os que não se reconhecem nos outros; não os oprimidos, os explorados, os que não são reconhecidos pelos que os oprimem como outro.

Após leitura, compartilhamento de impressões e exercícios de fixação e reflexão, os conceitos de Paulo Freire foram retomados com o filme nacional Que horas ela volta?, lançado em 2015 e dirigido por Anna Muylaert. Uma das questões apresentadas às(aos) alunas(os) ao final da leitura dos trechos selecionados já fazia a vinculação entre o texto e a película, ao perguntar se, no Brasil atual, elas(es) reconheciam alguma relação em que há opressores e oprimidos. 
Não são poucas as possibilidades de diálogo entre o pensamento de Paulo Freire em Pedagogia do Oprimido e as questões - tão atuais do Brasil - levantadas pelo filme. Para ilustrar, podemos, por exemplo, falar de como os opressores leem as (re)ações dos oprimidos como violência: "são sempre eles os 'violentos', os 'bárbaros' os 'malvados', os 'ferozes', quando reagem à violência dos opressores” (FREIRE, 1987, p. 24). A personalidade, o comportamento e o pensamento da personagem Jéssica, que não se conforma com as distinções da casa grande e da senzala e que enxerga a opressão sofrida por sua mãe, incomodam profundamente Dona Bárbara, que lê a jovem como rebelde, mal-educada. É esta mesma Jéssica que acredita que a educação (o ingresso no Ensino Superior) pode mudar sua condição de vida e se empenha na busca de seu direito. Quando perguntada por Dona Bárbara de onde vêm suas ideias, ela responde que seu professor de história sempre trazia para a aula questões que despertavam seu interesse e reflexão. Este professor da ficção parece ter conseguido operar a educação libertadora. Segundo Freire (1987, p. 38),

[a] educação que se impõe aos que verdadeiramente se comprometem com a libertação não pode fundarse numa compreensão dos homens como seres "vazios" a quem o mundo "encha" de conteúdos; não pode basear-se numa consciência especializada, mecanicistamente compartimentada, mas nos homens como "corpos conscientes" e na consciência como consciência intencionada ao mundo. Não pode ser a do depósito de conteúdos, mas a da problematização dos homens em suas relações com o mundo.

No recorte relatado, o conceito de "violência" foi destrinchado a partir de outros conceitos e no seio do problema filosófico da legitimidade da violência. Considerando que a violência é uma constante no dia a dia das/os brasileiras/os, as/os alunas/os já tinham vivências e opiniões sobre o tema. Algumas delas eram preconceitos ou falácias. O tratamento filosófico do conceito permitiu romper com visões do senso comum. Nesse movimento, as(os) estudantes puderam experimentar diferentes definições de violência, entendendo que conceitos se vinculam a uma rede de ideias.

Nessa proposta, a Filosofia esteve sempre em diálogo interdisciplinar e intertextual. Além da presença de recurso audiovisual (filme), provocamos a reflexão e a produção relacionando os diferentes aportes, como, por exemplo, texto-filme. Ainda, incitamos constantemente os alunos a pensar, a partir das ferramentas da filosofia, sua realidade e a realidade de nosso país.

\section{Considerações finais}

Neste artigo, tecemos considerações sobre três modelos de ensino de Filosofia. O ensino da Filosofia a partir de sua história recai em esquematismos que não dão conta de tratar os problemas filosóficos. Por outro lado, a contextualização histórica pode ser um valioso elemento para a compreensão de um problema da Filosofia. Ao avaliarmos um problema filosófico junto às(aos) alunas(os), não só promovemos a Filosofia, mas também o filosofar. Ainda, são os problemas que guardam as ideias e conceitos da Filosofia como eles o são: um questionamento e uma demanda por argumentarmos na defesa de nossas posições, ouvirmos outras posições e nos convencermos por um ou outro entendimento. Entretanto, os problemas filosóficos são complexos, o que requer estratégias para sua abordagem. Para superarmos essa dificuldade, escolhemos os conceitos como fio condutor de nossas práticas. Conceitos são, como advogam muitos pensadores, a matéria-prima da Filosofia e também sua criação. Os conceitos, ao guardarem definições e sentidos, promovem um trabalho de linguagem, sendo esta uma das mais fortes tendências da Filosofia no século XX e XXI. A análise conceitual é, ainda, uma excelente ferramenta interdisciplinar para a Filosofia, pois se põe a serviço de outras áreas, investigando os seus conceitos. Como uma proposta pedagógica para o ensino de Filosofia na educação básica, a análise conceitual se coloca como uma alternativa conciliatória ao binômio História x problemas. Por um lado, permite a contextualização; por outro, põe em destaque por o que se pergunta filosoficamente e também os possíveis sentidos das palavras que compõem um problema. Com o exemplo de prática de sala de aula, demonstramos ser possível o trabalho com conceitos na educação 
básica como fio condutor da atividade filosófica e da interdisciplinaridade. Compartilhamos neste trabalho nosso estudo e nossa escolha por acreditarmos que eles poderão contribuir com a área de Ensino de Filosofia e também com as(os) docentes que atuam na educação básica. Nesse sentido, rememoramos as funções de um Colégio de Aplicação no que tange à inovação pedagógica. Uma vez que o projeto pedagógico da área de Filosofia do CAp-UFRGS ainda está em construção, continuaremos fazendo leituras que qualifiquem o documento e o trabalho da área, e também seguiremos experimentando a análise conceitual em sala de aula.

\section{Referências}

DELEUZE, Gilles; GUATTARI, Félix. O que é a filosofia? Tradução de Bento Prado Jr. e Alberto Alonso Muñoz. 3. ed. São Paulo: Editora 34, 2010.

FREIRE, Paulo. Pedagogia da autonomia. 25. ed. São Paulo: Paz e Terra, 2002.

FREIRE, Paulo. Pedagogia do oprimido. 11. ed. São Paulo: Paz e Terra, 1987.

GALLO, Sílvio; KOHAN, Walter Omar. Crítica de alguns lugares-comuns ao se pensar a filosofia no Ensino Médio. In: GALLO, Sílvio; KOHAN, Walter Omar (org.). Filosofia no ensino médio. 3. ed. Petrópolis: Vozes, 2000. v. VI, p. 174-196.

HORN, Geraldo Balduíno. A presença da filosofia no currículo do Ensino Médio brasileiro: uma perspectiva histórica. In: GALLO, Sílvio; KOHAN, Walter Omar (org.). Filosofia no ensino médio. 3. ed. Petrópolis: Vozes, 2000. v. VI, p. 17-33.

MARCONDES, Danilo. É possível ensinar a filosofia? E, se possível, como? In: KOHAN, Walter Oman (org.). Filosofia: caminhos para seu ensino. Rio de Janeiro: DP\&A, 2004. p. 54-68.

NOGUERA, Renato. O ensino de filosofia e a lei 10.639. Rio de Janeiro: Pallas, 2014.

PORTA, Mario Ariel Gonzalez. A Filosofia a partir de seus problemas. 4. ed. São Paulo: Loyola, 2014.

QUE HORAS ela volta? Direção: Anna Muylaert. Produção: Anna Muylaert, Débora Ivanov, Caio Gullane, Fabiano Gullane. Rio de Janeiro: Globo Filmes, 2015. Streaming.

ROCHA, Ronai Pires da. Ensino de Filosofia e currículo. Santa Maria: Editora UFSM, 2015.

ROUANET, Sergio Paulo. Reinventando as humanidades. In: ROUANET, Sergio Paulo. As razões do Iluminismo. 1 ed. São Paulo: Companhia das Letras, 1987. p. 304-330.

VELASCO, Patrícia Del Nero. Ensino de Filosofia como campo de conhecimento. Estudos de Filosofia e Ensino, Rio de Janeiro, v. 1, n. 1, p. 6-21, 2019. Disponível em: https://revistas.cefet-rj.br/index.php/estudosdefilosofiaeensino/article/view/419. Acesso em: 14 ago. 2020.

WILSON, John. Pensar com conceitos. São Paulo: Martins Fontes, 2005.

Data de submissão: 18/06/2020

Data de aceite: 10/09/2020 